\title{
Hurricane Sandy Evacuation Among World Trade Center Health Registry Enrollees in New York City
}

\author{
Shakara Brown, MPH; Lisa M. Gargano, PhD, MPH; Hilary Parton, MPH; \\ Kimberly Caramanica, MPH; Mark R. Farfel, ScD; Steven D. Stellman, PhD, MPH; \\ Robert M. Brackbill, PhD, MPH
}

\section{ABSTRACT}

Objective: Timely evacuation is vital for reducing adverse outcomes during disasters. This study examined factors associated with evacuation and evacuation timing during Hurricane Sandy among World Trade Center Health Registry (Registry) enrollees.

Methods: The study sample included 1162 adults who resided in New York City's evacuation zone A during Hurricane Sandy who completed the Registry's Hurricane Sandy substudy in 2013. Factors assessed included zone awareness, prior evacuation experience, community cohesion, emergency preparedness, and poor physical health. Prevalence estimates and multiple logistic regression models of evacuation at any time and evacuation before Hurricane Sandy were created.

Results: Among respondents who evacuated for Hurricane Sandy (51\%), 24\% had evacuated before the storm. In adjusted analyses, those more likely to evacuate knew they resided in an evacuation zone, had evacuated during Hurricane Irene, or reported pre-Sandy community cohesion. Evacuation was less likely among those who reported being prepared for an emergency. For evacuation timing, evacuation before Hurricane Sandy was less likely among those with pets and those who reported 14 or more poor physical health days.

Conclusions: Higher evacuation rates were observed for respondents seemingly more informed and who lived in neighborhoods with greater social capital. Improved disaster messaging that amplifies these factors may increase adherence with evacuation warnings. (Disaster Med Public Health Preparedness. 2016; page 1 of 9)

Key Words: disasters, emergency preparedness, community support, 9/11, zone awareness

$\mathrm{H}$ urricane Sandy was one of the most devastating hurricanes to hit the United States, causing approximately $\$ 65$ billion dollars in damages, destroying 650,000 homes, and leaving 8.5 million people without power. ${ }^{1}$ Neighborhoods in low-lying areas and along the coast of New York City (NYC) were among the most heavily affected. ${ }^{2,3}$ In anticipation of Hurricane Sandy in October 2012, NYC officials broadcasted storm updates and alerted millions of residents through established networks such as a web page and the mayor's YouTube channel. Emergency alerts were also sent to residents through various modes of communication, including Twitter, land lines, cell phones, and e-mail. ${ }^{2}$

In 2012, the NYC coastal storm plan had 3 evacuation zones $(\mathrm{A}, \mathrm{B}$, and $\mathrm{C})$ categorized according to risk of storm surge impact. To reduce negative impacts during Sandy, residents in evacuation zone A, the zone most vulnerable to coastal storm flooding and damages, were instructed to evacuate. ${ }^{2,4}$ Despite advance warning, only $37 \%$ of zone A residents evacuated before, during, or after the storm. ${ }^{5}$
Evacuation is effective in preventing adverse outcomes during disasters, including injuries related to exposures to post-storm elements. ${ }^{6-9}$ The decision to evacuate is often influenced by multiple factors. Several studies among Hurricane Katrina survivors found that evacuation was hindered by misperceptions about evacuation procedures either because of the timing of the warning or its lack of clarity, or because of a lack of transportation. ${ }^{10-12}$ Those with large families and limited resources, and the elderly who were reluctant or physically constrained, struggled to evacuate. ${ }^{10} \mathrm{~A}$ study of California flood survivors in 1997 found that having pets increased evacuation failure, as many were hampered by the logistics of evacuating with their pets, particularly if they had more than one. ${ }^{13}$ Other factors associated with evacuation failure include being male, perceived social inequity, not having all members of the household together, low risk perception, underestimating potential storm destructiveness, and poor physical health. ${ }^{10-12,14-20} \mathrm{We}$ are aware of only one study that has examined evacuation behaviors among those previously exposed to a disaster. ${ }^{21}$ 
A better understanding of factors that influence evacuation behaviors may help local officials improve evacuation efforts in future disasters. In this study we aimed to identify factors associated with evacuation and early or pre-storm evacuation for Hurricane Sandy among individuals previously exposed to the World Trade Center (WTC) attacks on September 11, $2001(9 / 11)$.

\section{METHODS}

\section{Study Design and Sample Selection}

The WTC Health Registry (Registry) is a longitudinal cohort created to monitor the health of persons exposed to the $9 / 11$ disaster. In 2003-2004, the Registry enrolled and surveyed 71,430 individuals exposed to the events of 9/11 (Wave 1); follow-up information for enrollees was obtained through subsequent surveys in 2006-2007 (Wave 2) and 2011-2012 (Wave 3). Specific details on Registry recruitment and data collection methods have been described elsewhere, ${ }^{22}$ and the physical and mental health effects of $9 / 11$ on Registry enrollees have also been previously reported. ${ }^{22,23}$

At the end of the Wave 3 data collection period in March 2012, there were 43,175 completed surveys (63\% response rate). Hurricane Sandy occurred within months of the Wave 3 survey, presenting a unique opportunity to study evacuation behaviors among Registry enrollees, who then became the sampling pool for a new questionnaire-based substudy. The present analysis assessed the impact of Hurricane Sandy on both physical and mental health, with special attention to evacuation practice and timing in a unique population of individuals previously exposed to a large-scale disaster.

During Hurricane Sandy, the Federal Emergency Management Agency (FEMA) Modeling Task Force was mobilized to assess and estimate the degree of storm impact based on flood depths, which was later used to create surge boundaries, also known as inundation zones. For the Hurricane Sandy substudy, adult enrollees in the tri-state area (New York, New Jersey, and Connecticut) were classified into 2 groups based on residence: those who lived in a Sandy inundation zone as defined by FEMA $(\mathrm{N}=4435)$ and a comparison group of the same size $(\mathrm{N}=4435)$, randomly selected, who did not reside in an inundation zone. These 8870 individuals were invited to participate in a web-based or paper survey beginning March 28, 2013, approximately 5 months after Sandy. In an effort to increase response rates, multiple reminders were sent via mail and e-mail to enrollees who had not yet completed the survey. Data collection continued through early November 2013, resulting in 4558 (inundation zone, $\mathrm{N}=2443$; noninundation zone, $\mathrm{N}=2115$ ) completed surveys $(51.4 \%$ response rate).

For these analyses, only enrollees with a NYC zip code in zone A who had complete information on their evacuation status were included, as mandatory evacuation orders were issued for zone A by NYC officials in anticipation of Hurricane Sandy $(\mathrm{N}=1162)$. The study was approved by the NYC Department of Health and Mental Hygiene's Institutional Review Board.

\section{Hurricane Sandy Evacuation Variables}

Participants were asked, "At any time before, during or after the storm did you evacuate from your home?" Those who responded yes were then asked when they evacuated: before Sandy arrived (October 29, 2012), during the storm (October 29-30, 2012), after Sandy had hit (later on October 30, 2012), or after the storm had passed (on or after October 31, 2012). For timing in this analysis, evacuation before the storm was compared to evacuation during or after.

\section{Demographic Variables}

Sociodemographic characteristics were assessed by using information from prior Registry survey waves and from the Sandy survey. Variables from the Sandy survey included gender and age group at the time of survey administration. Registry variables included education at Wave 1 , race/ethnicity, household income in 2010, and marital status at Wave 3.

\section{Hurricane Sandy Survey Variables}

Exposures assessed at the time of the Sandy survey included being at or near home when Hurricane Sandy made landfall (yes/no), household damage (eg, damaged but livable or damaged and uninhabitable/destroyed), and residence in an inundation zone as defined by FEMA.

We also included variables that may have affected evacuation behaviors during the storm, including floor of residence (6th floor or lower; 7th floor or higher), evacuation zone awareness prior to Sandy, emergency preparedness, and prior disaster experience. Emergency preparedness was defined similarly to other studies. ${ }^{24,25}$ Respondents were considered prepared if they were missing no more than 1 of 8 preparedness items, including a supply of nonperishable food, 3 days' supply of water, first aid kit, flashlight, battery-operated radio, personal care and hygiene items, all needed medications, and an evacuation plan. Having or not having an evacuation plan was also considered as a separate dichotomous variable. Prior evacuation experience was measured by using a binary variable for evacuation during Hurricane Irene in August 2011.

Measures that reflected household responsibilities and support included the number of people in the household, having a child younger than 18 years of age in the home, pet ownership, and community cohesion. A 3-level household size variable was created based on the distribution of responses of the number of people in the household (1-2, 3-4, 5 or more). A binary variable was created from reported age groups of household members to measure whether respondents had a child younger than 18 years of age in the home. Evacuees were 
also asked about the evacuation of pets; responses were used to define a binary variable on pet ownership. Community cohesion prior to Sandy was measured by level of agreement with the statement, "Before Sandy, my neighborhood was close-knit or unified." For our analysis, responses were collapsed to 3 levels indicating agreement (strongly agree, somewhat agree), disagreement (somewhat disagree, strongly disagree), or neutrality (neither agree nor disagree).

\section{Hurricane Sandy Registry Survey Variables}

Consistent with other studies, ${ }^{26,27}$ respondents were classified as having poor physical or mental health if they reported 14 or more days in the past 30 days in which their physical or mental health was not good. A binary measure for prior trauma was created from a summary traumatic life event score at Wave 3, similar to that used in a previous Registry study of Hurricane Sandy-related post-traumatic stress disorder (PTSD). ${ }^{28}$ This score was based on the sum of 8 traumatic life events excluding 9/11, such as experiencing a serious accident, natural or manmade disaster, assault with or without a weapon, unwanted sexual contact, or a life-threatening illness.

Probable 9/11-related PTSD was assessed at all 3 Registry survey waves by using the 17 -item PTSD Checklist-Civilian Version (PCL-17). The scale reflects criteria set by the Diagnostic and Statistical Manual of Mental Disorders (4th edition), and was adapted to be 9/11-specific and recent (within the past 30 days). Severity of symptoms was rated on a 5 -point Likert scale from not at all to extremely. Probable PTSD was defined as having a PCL-17 score $\geq 44$ at any wave. $^{23,28,29}$ A 12 -item summary measure was used to define 9/11-related exposure and was categorized as some exposure ( 2 or more) or little to none ( 0 to 1 exposure). ${ }^{28}$ Social support was assessed at Wave 3 and was based on a 5-point Likert scale reflecting how often someone was available to take you to the doctor, have a good time with, hug, prepare meals if unable to do so by oneself, and understand problems; a summary score was calculated. ${ }^{30}$ On the basis of the frequency distribution of survey responses, scores were categorized into 3 levels of support (low: 1-8, medium: 9-16, high: 17-25).

\section{Data Analysis}

Univariate statistics were used to describe evacuees and nonevacuees by sociodemographic factors, physical and mental health indicators, and other respondent characteristics. Bivariate analyses were conducted by using chi-square to test for associations between these measures and evacuation status (significance was defined as $P<0.05$ ). A multiple logistic regression model adjusted for demographic variables, variables significant at the bivariate level, and other variables previously reported to be associated with evacuation was used to describe evacuation at any time.

Chi-square was used to test the association between evacuation timing and factors significantly associated with evacuation at any time as well as other variables previously reported in the literature. A multiple logistic regression model was used to identify predictors of evacuation before Sandy made landfall with control for potential confounders. With the exception of demographic variables, only significant predictors were included in the regression model $(P<0.05)$. All analyses were performed by using SAS software version 9.2 (SAS Institute Inc, Cary, NC).

\section{RESULTS}

Respondents in evacuation zone A were evenly split by gender, were primarily 45 to 64 years of age, had a college or postgraduate education, were white non-Hispanic, had a 2010 household income $<\$ 50,000$, and were married or living with a partner (Table 1). The majority of respondents in evacuation zone $\mathrm{A}$ also resided in a FEMA-defined inundation zone (85\%; Figure 1). Approximately half of the respondents reported evacuating at any time before, during, or after Sandy (51\%), and of those, 24\% evacuated before the storm (Table 1). Most respondents were in the area when Sandy made landfall (76\%), and only $42 \%$ of these respondents evacuated. Less than one-quarter of respondents reported that their home was damaged and uninhabitable or destroyed as a result of Sandy (21\%; data not shown).

Table 2 compares several evacuation and preparedness factors and health outcomes among zone A residents who evacuated and those who did not. Evacuees were more likely to know they lived in an evacuation zone $(78 \%$ vs. $54 \%, P<0.001)$, to have evacuated during Hurricane Irene $(51 \%$ vs. $24 \%$, $P<0.001$ ), to have a child younger than 18 years of age in the home ( $29 \%$ vs. $23 \%, P=0.01$ ), and to have perceived strong community cohesion prior to Sandy ( $57 \%$ vs. $44 \%$, $P<0.001)$. However, there were no significant differences in evacuation by floor residence, emergency preparedness, evacuation plan, household size, poor physical or mental health days, traumatic life events after 9/11, 9/11-related PTSD, 9/11-related exposure, or social support.

Multiple regression results predicting Sandy evacuation at any time are shown in Table 3. Individuals reporting 14 or more poor physical health days were significantly less likely to evacuate for Hurricane Sandy (adjusted odds ratio [AOR]: 0.69; $95 \%$ confidence interval [CI]: 0.49-0.98) than were those with $<14$ poor physical health days. Compared to those with no knowledge of residing in an evacuation zone, those who reported they knew they lived in an evacuation zone were almost twice as likely to evacuate (AOR: 1.82; 95\% CI: 1.24-2.65), whereas those who incorrectly reported they did not live in an evacuation zone were nearly half as likely to evacuate (AOR: 0.55; 95\% CI: 0.34-0.90). Respondents who reported evacuating during Hurricane Irene were more than twice as likely to evacuate during Hurricane Sandy as were those who did not evacuate for Hurricane Irene (AOR: 2.41; 95\% CI: 1.79-3.26). Furthermore, those who agreed or 
TABLE 1

Sociodemographic Characteristics and Hurricane Sandy Evacuation Status Among Adult World Trade Center Health Registry Enrollees Residing in New York City Evacuation Zone $\mathbf{A}^{\mathrm{a}}$

\begin{tabular}{|c|c|c|}
\hline & \multicolumn{2}{|c|}{$\begin{array}{l}\text { Evacuation Zone } A \\
\quad(\mathrm{~N}=1162)\end{array}$} \\
\hline & No. & $\%$ \\
\hline \multicolumn{3}{|l|}{ Gender } \\
\hline Male & 591 & 50.9 \\
\hline Female & 571 & 49.1 \\
\hline \multicolumn{3}{|l|}{ Age Group at Hurricane Sandy, years } \\
\hline $18-29$ & 31 & 2.7 \\
\hline $30-44$ & 160 & 13.8 \\
\hline $45-64$ & 718 & 61.8 \\
\hline$\geq 65$ & 253 & 21.8 \\
\hline \multicolumn{3}{|l|}{ Education at Wave 1} \\
\hline High school or less/GED & 319 & 27.5 \\
\hline Some college & 231 & 19.9 \\
\hline College/postgraduate & 611 & 52.6 \\
\hline \multicolumn{3}{|l|}{ Race/Ethnicity } \\
\hline White non-Hispanic & 812 & 69.9 \\
\hline Black non-Hispanic & 81 & 7.0 \\
\hline Hispanic & 139 & 12.0 \\
\hline Asian/other ${ }^{\mathrm{b}}$ & 130 & 11.2 \\
\hline \multicolumn{3}{|l|}{ Household Income in 2010} \\
\hline$<\$ 50 K$ & 362 & 32.9 \\
\hline$\$ 50 K-\$ 75 K$ & 185 & 16.8 \\
\hline$\$ 75-\$ 150 k$ & 341 & 31.0 \\
\hline$>\$ 150 k$ & 212 & 19.3 \\
\hline \multicolumn{3}{|l|}{ Marital Status at Wave 3} \\
\hline Married/not married, living with partner & 688 & 59.8 \\
\hline Widowed/divorced/separated & 235 & 20.4 \\
\hline Never married & 227 & 19.7 \\
\hline \multicolumn{3}{|l|}{ Residence in Inundation Zone } \\
\hline Yes & 991 & 85.3 \\
\hline No & 171 & 14.7 \\
\hline \multicolumn{3}{|l|}{ Evacuation Status } \\
\hline Evacuated before & 273 & 24.3 \\
\hline Evacuated during/after & 300 & 26.7 \\
\hline Did not evacuate & 550 & 49.0 \\
\hline
\end{tabular}

aZone A zip codes include 10004, 10005, 10006, 10009, 10038, 10280, 10282, 10303, 10305, 10306, 10307, 10309, 10314, 11096, 11109, 11224, 11231, 11235, 11691, 11692, 11693, 11694, 11695, and 11697.

bIncludes Native Hawaiian, other Pacific Islander, other non-Hispanic such as multiple races and American Indian or Alaska Native.

strongly agreed that their community was close-knit prior to Sandy were almost $60 \%$ more likely to evacuate than were those who disagreed or were neutral (AOR: 1.62; 95\% CI: 1.23-2.14). Last, those who reported being prepared for an emergency were less likely to evacuate during Sandy than were those who were not prepared (AOR: $0.72 ; 95 \% \mathrm{CI}$ : 0.54-0.95; Table 3).

Similar findings were observed in the regression model predicting evacuation before Hurricane Sandy compared with those who evacuated during or after (Table 4). Respondents who knew they lived in an evacuation zone (AOR: 2.17; 95\% CI: 1.13-4.17) and those who evacuated for Hurricane Irene (AOR: 3.15; 95\% CI: 2.06-4.81) were more likely to have evacuated before Hurricane Sandy. Those with poorer physical health (AOR: 0.38; 95\% CI: 0.21-0.66) and those who incorrectly reported that they did not live in an evacuation zone (AOR: $0.20 ; 95 \% \mathrm{CI}$ : 0.06-0.68) were less likely to evacuate before than during or after. Furthermore, females were almost twice as likely as males to evacuate before Sandy (AOR: 1.94; 95\% CI: 1.25-3.01), and compared to younger adults, adults 65 years of age or older were nearly four times as likely to evacuate before as during or after the storm (AOR: 3.84; 95\% CI: 1.89-7.84). Compared to those with an income $>\$ 150,000$, those with a 2010 household income of $\$ 50,000$ to $\$ 75,000$ were less likely to evacuate before Sandy made landfall (AOR: 0.37; 95\% CI: 0.19-0.73). Similarly, respondents who reported owning pets were also less likely to evacuate before Hurricane Sandy (AOR: 0.56; 95\% CI: 0.37-0.86).

\section{DISCUSSION}

Approximately half of Registry enrollees residing in NYC evacuation zone A evacuated during Hurricane Sandy. Compliance with the mayor's evacuation order was higher among respondents who had prior evacuation experience, who were aware that they resided in an evacuation zone, and who had perceived community cohesion prior to the storm. Evacuation was lower among those who reported being prepared for an emergency, those who had poor physical health, and those who had pets.

Because persons previously exposed to a disaster may have heightened sensitivity to the effects of a disaster, ${ }^{31}$ we hypothesized that WTC disaster survivors would be more motivated to evacuate for Hurricane Sandy. However, we did not find an association between 9/11 exposures or 9/11 related PTSD and evacuation. Nonetheless, respondents who evacuated during Hurricane Irene were more likely to evacuate for Hurricane Sandy. This finding is consistent with other disaster studies that found that prior evacuation experiences were an important factor in deciding to evacuate. $^{15,20,32}$ Specifically, such experiences provide the framework by which individuals can replicate their behaviors, ${ }^{15}$ making it easier to respond. One potential explanation for this difference in evacuation behaviors may be due to the fact that Hurricane Sandy and the WTC attacks were different types of disasters. The importance of preemptive evacuation warning and evacuation is reflected in those who evacuated for Hurricane Irene, since those who evacuated were more likely to evacuate for Hurricane Sandy. Another potential explanation for this observed difference is that the events of 9/11 occurred more than a decade before Sandy, whereas Hurricane Irene was a little more than a year prior. The association between 9/11 measures and Hurricane Sandy may have been attenuated owing to the large time gap between events. 
Distribution of Study Population in Evacuation Zone A in 2012.

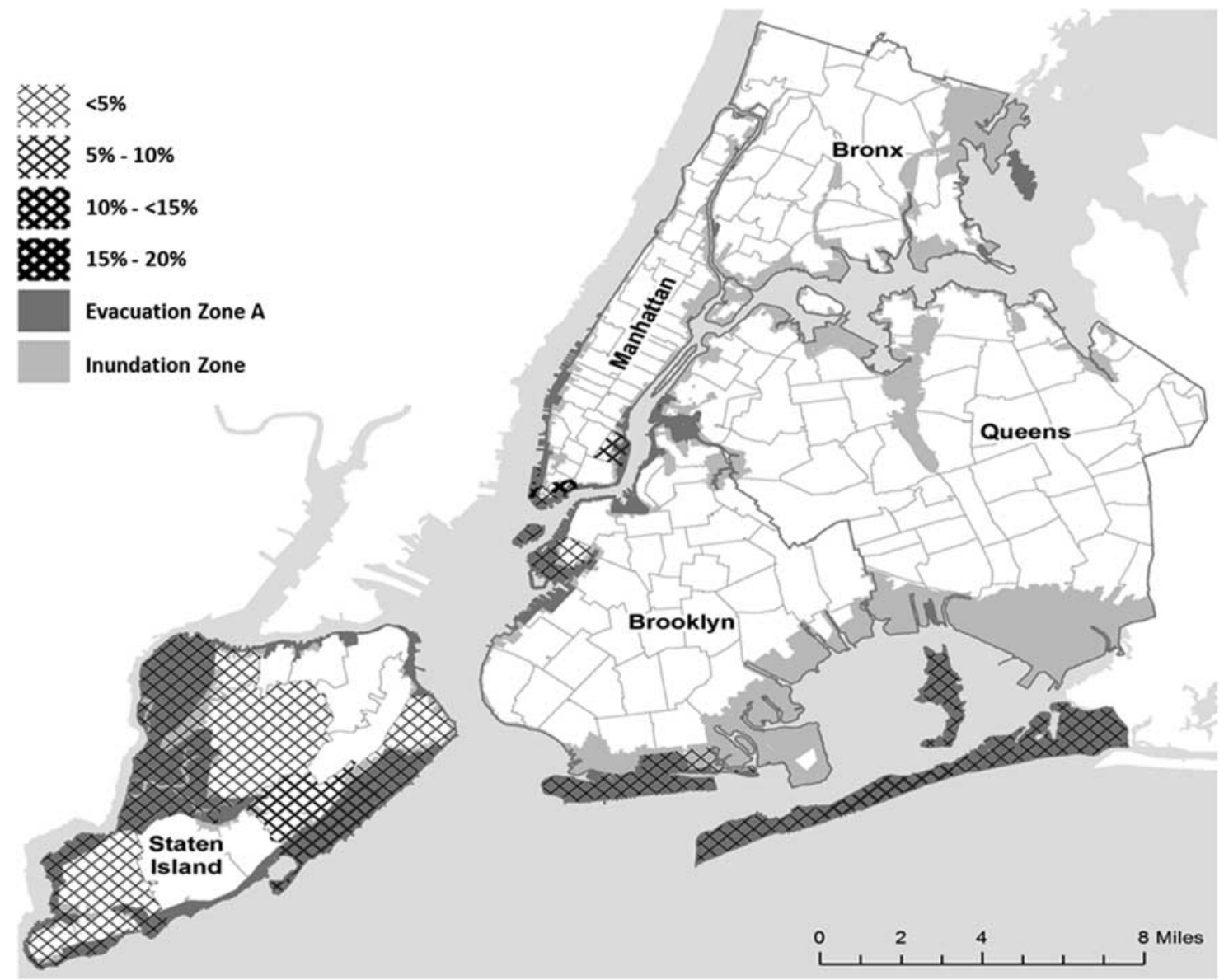

The lower likelihood of evacuation among respondents who were considered prepared for an emergency is unexpected. We hypothesized that during an emergency, prepared individuals would be more likely to evacuate, especially because preparedness included having an evacuation plan. However, in our study, having an evacuation plan was not associated with evacuation, and those who were prepared were $28 \%$ less likely to have evacuated for Sandy. A possible explanation for this finding is that the definition used in this study (having 7 or more preparedness items) speaks more to preparing to stay or shelter in place rather than preparing to leave. Thus, regardless of having an evacuation plan, if preparedness items are not "travel-ready," evacuation may be unlikely.

Persons with pets were $44 \%$ less likely to evacuate before Hurricane Sandy. Other studies have also shown that many pet owners will not evacuate if they are unable to take their pets with them. ${ }^{13,33,34}$ Although NYC shelters accommodate pets during hurricanes, ${ }^{35,36}$ residents may have been unaware they could bring their pets to a shelter during Hurricane Sandy. Following Hurricane Sandy, the City of New York created the Public Health Emergency Network (PHEN) website to better inform residents on how to adequately prepare for and respond to disasters. The PHEN website includes information on pet evacuation and emergency supplies needed in case evacuation becomes necessary for individual New Yorkers and their families. ${ }^{37}$

Poor physical health was negatively associated with evacuation, which is consistent with other disaster research. ${ }^{16-18}$ Lower evacuation among this group may be due to underlying disabilities, such as ambulatory difficulties that make it difficult or impossible to access emergency services and evacuate safely. In 2013, NYC settled a lawsuit brought on behalf of the disabled in emergencies and committed to providing better communications, transportation, evacuation, and shelter for the disabled during disasters. ${ }^{38}$ To ensure all New Yorkers are able to safely evacuate, the city has begun developing an extensive canvassing operation to assess the needs of all impacted individuals immediately after a disaster and provide evacuation assistance to those with functional needs. This novel initiative focuses on working with 


\section{TABLE 2}

\section{Prevalence of Evacuation at Any Time Among Adult World Trade Center Health Registry Enrollees Residing in New York City Evacuation Zone $A^{a}$}

\begin{tabular}{|c|c|c|c|c|c|}
\hline & \multicolumn{2}{|c|}{ Evacuated $(\mathrm{N}=612)$} & \multicolumn{2}{|c|}{ Did Not Evacuate $(\mathrm{N}=550)$} & \multirow[b]{2}{*}{$P$} \\
\hline & No. & $\%$ & No. & $\%$ & \\
\hline \multicolumn{6}{|l|}{ Hurricane Sandy Variables } \\
\hline \multicolumn{6}{|l|}{ Floor Residence } \\
\hline 6th floor or lower & 401 & 66.0 & 361 & 66.0 & \multirow[t]{2}{*}{0.988} \\
\hline 7th floor or higher & 207 & 34.0 & 186 & 34.0 & \\
\hline \multicolumn{6}{|l|}{ Evacuation Zone Awareness } \\
\hline Knew lived in an evacuation zone & 475 & 77.9 & 292 & 53.5 & \multirow[t]{3}{*}{$<0.001$} \\
\hline Knew did not live in an evacuation zone & 55 & 9.0 & 148 & 27.1 & \\
\hline Did not know about zone & 80 & 13.1 & 106 & 19.4 & \\
\hline \multicolumn{6}{|l|}{ Emergency Preparedness } \\
\hline Prepared & 208 & 34.0 & 217 & 39.5 & \multirow[t]{2}{*}{0.053} \\
\hline Not prepared & 404 & 66.0 & 333 & 60.5 & \\
\hline \multicolumn{6}{|l|}{ Evacuation Plan } \\
\hline Yes & 231 & 37.7 & 178 & 32.4 & \multirow[t]{2}{*}{0.055} \\
\hline No & 381 & 62.3 & 372 & 67.6 & \\
\hline \multicolumn{6}{|l|}{ Evacuation During Hurricane Irene } \\
\hline Evacuated & 292 & 51.0 & 126 & 23.5 & \multirow[t]{2}{*}{$<0.0001$} \\
\hline Did not evacuate & 281 & 49.0 & 411 & 76.5 & \\
\hline \multicolumn{6}{|l|}{ Number of People in Household } \\
\hline $1-2$ & 347 & 57.4 & 325 & 59.4 & \multirow[t]{3}{*}{0.175} \\
\hline $3-4$ & 187 & 30.9 & 176 & 32.2 & \\
\hline$\geq 5$ & 71 & 11.7 & 46 & 8.4 & \\
\hline \multicolumn{6}{|l|}{ Child in Home (<18 years) } \\
\hline Yes & 179 & 29.2 & 126 & 22.9 & \multirow[t]{2}{*}{0.014} \\
\hline No & 433 & 70.8 & 424 & 77.1 & \\
\hline \multicolumn{6}{|l|}{ Community Cohesion Prior to Sandy } \\
\hline Strongly agree/agree & 342 & 57.4 & 234 & 43.7 & \multirow[t]{3}{*}{$<0.001$} \\
\hline Neutral & 193 & 32.4 & 250 & 46.6 & \\
\hline Strongly disagree/Somewhat disagree & 61 & 10.2 & 52 & 9.7 & \\
\hline Registry Variables & & & & & \\
\hline Poor Physical Health Days & & & & & \\
\hline$\geq 14$ days & 109 & 18.3 & 125 & 23.0 & 0.050 \\
\hline$<14$ days & 487 & 81.7 & 419 & 77.0 & \\
\hline Poor Mental Health Days & & & & & \\
\hline$\geq 14$ days & 139 & 23.4 & 131 & 24.1 & 0.762 \\
\hline$<14$ days & 456 & 76.6 & 412 & 75.9 & \\
\hline Traumatic Life Events Since 9/11 & & & & & \\
\hline Yes & 183 & 30.3 & 179 & 32.8 & 0.365 \\
\hline No & 421 & 69.7 & 367 & 67.2 & \\
\hline 9/11-Related Post-Traumatic Stress Disorder & & & & & \\
\hline Yes & 186 & 35.8 & 171 & 36.1 & 0.920 \\
\hline No & 334 & 64.2 & 303 & 63.9 & \\
\hline 9/11 Exposure & & & & & \\
\hline Some ( $\geq 2$ Exposures) & 459 & 75.0 & 402 & 73.1 & 0.458 \\
\hline Little to none (0-1 Exposures) & 153 & 25.0 & 148 & 26.9 & \\
\hline Level of Social Support & & & & & \\
\hline Low $(1-8)$ & 49 & 8.2 & 50 & 9.2 & 0.590 \\
\hline Medium (9-16) & 164 & 27.4 & 159 & 29.3 & \\
\hline High (17-25) & 385 & 64.4 & 334 & 61.5 & \\
\hline
\end{tabular}

aZone A zip codes include 10004, 10005, 10006, 10009, 10038, 10280, 10282, 10303, 10305, 10306, 10307, 10309, 10314, 11096, 11109, 11224, 11231, 11235, 11691, 11692, 11693, 11694, 11695, and 11697.

community-based organizations, health care providers, and emergency services to provide comprehensive outreach to vulnerable populations before, during, and after a disaster and those who choose to shelter in place. ${ }^{39}$
The finding that those who knew they resided in an evacuation zone were more likely to evacuate before Hurricane Sandy is consistent with previous studies regarding information received during disasters. ${ }^{15,16,21}$ The more 
TABLE 3

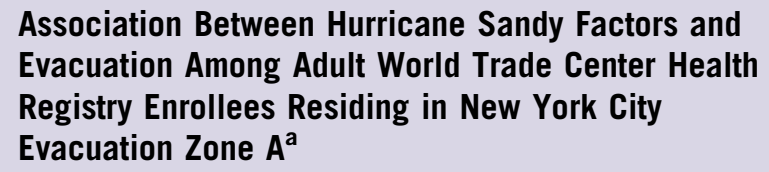

\begin{tabular}{|c|c|c|c|}
\hline & \multirow[b]{2}{*}{ AOR } & \multicolumn{2}{|c|}{$95 \% \mathrm{Cl}$} \\
\hline & & Lower & Upper \\
\hline \multicolumn{4}{|l|}{ Poor Physical Health Days } \\
\hline$\geq 14$ days & $0.69^{\mathrm{b}}$ & 0.49 & 0.98 \\
\hline$<14$ days & Ref & - & - \\
\hline \multicolumn{4}{|l|}{ Zone Awareness } \\
\hline Knew lived in an evacuation zone & $1.82^{\mathrm{b}}$ & 1.24 & 2.65 \\
\hline Knew did not live in an evacuation zone & $0.55^{\mathrm{b}}$ & 0.34 & 0.90 \\
\hline Did not know about zone & Ref & - & - \\
\hline \multicolumn{4}{|l|}{ Evacuation During Hurricane Irene } \\
\hline Evacuated & $2.41^{\mathrm{b}}$ & 1.79 & 3.26 \\
\hline Did not evacuate & Ref & - & - \\
\hline \multicolumn{4}{|l|}{ Community Cohesion Prior to Hurricane Sandy } \\
\hline Strongly agree/agree & $1.62^{\mathrm{b}}$ & 1.23 & 2.14 \\
\hline Neutral/strongly disagree/somewhat disagree & Ref & - & - \\
\hline \multicolumn{4}{|l|}{ Emergency Preparedness } \\
\hline Prepared & $0.72^{\mathrm{b}}$ & 0.54 & 0.95 \\
\hline Not prepared & Ref & - & - \\
\hline
\end{tabular}

${ }^{\mathrm{a} A b b r e v i a t i o n s: ~} \mathrm{AOR}$, adjusted odds ratio; $\mathrm{Cl}$, confidence interval; Ref, referent category. Zone A zip codes include 10004, 10005, 10006, 10009, 10038, 10280, 10282, 10303, 10305, 10306, 10307, 10309, 10314, 11096, 11109, 11224, 11231, 11235, 11691, 11692, 11693, 11694, 11695, and 11697. Covariates include race/ethnicity, gender, age-group at time of Sandy, education level, and household income.

bignificant at $P<0.05$.

informed individuals are during a disaster, the more likely they are to believe the event is a serious threat, and evacuate. Additionally, we found that evacuation prior to Hurricane Sandy's arrival was higher among females, consistent with other research findings. ${ }^{14}$ During Sandy, the NYC Fire Department's Incident Management Team was responsible for coordinating and executing the evacuation of NYC's homebound population, which tends to be older. ${ }^{2}$ This may partially explain why evacuation before Hurricane Sandy was higher among older adults. After Sandy, the NYC Office of Emergency Management created the Know Your Zone Campaign in an effort to improve evacuation zone awareness by informing residents on their current evacuation zones, potential risks during hurricanes, and emergency preparedness. $^{4}$

Interestingly, community cohesion was associated with evacuation but individual-level social support was not. Unlike individual social support, community cohesion measures the attachment each individual has to the group. Hence, evacuation might be influenced more by the bonds of group cohesiveness and the effects of social norms rather than those of individual-level social support. Interventions tailored toward strengthening these links among members of a community may improve evacuation compliance.
TABLE 4

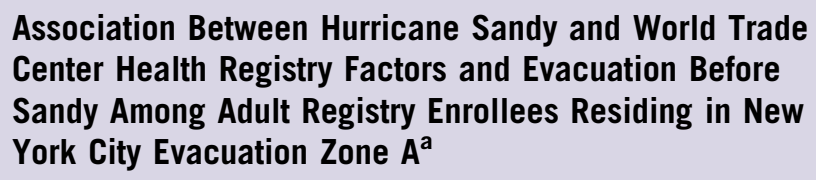

\begin{tabular}{|c|c|c|c|}
\hline & \multirow[b]{2}{*}{ AOR } & \multicolumn{2}{|c|}{$95 \% \mathrm{Cl}$} \\
\hline & & Lower & Upper \\
\hline \multicolumn{4}{|l|}{ Gender } \\
\hline Male & Ref & - & - \\
\hline Female & $1.94^{\mathrm{b}}$ & 1.25 & 3.01 \\
\hline \multicolumn{4}{|l|}{ Age Group at Hurricane Sandy, years } \\
\hline $18-44$ & Ref & - & - \\
\hline $45-64$ & 1.94 & 1.12 & 3.35 \\
\hline$\geq 65$ & $3.84^{\mathrm{b}}$ & 1.89 & 7.84 \\
\hline \multicolumn{4}{|l|}{ Household Income in 2010} \\
\hline$<\$ 50 K$ & 0.66 & 0.34 & 1.29 \\
\hline$\$ 50 K-\$ 75 K$ & $0.37^{b}$ & 0.19 & 0.73 \\
\hline$\$ 75 K-\$ 150 K$ & 0.52 & 0.29 & 0.93 \\
\hline$>\$ 150 \mathrm{k}$ & Ref & - & - \\
\hline \multicolumn{4}{|l|}{ Pet Ownership } \\
\hline Yes & $0.56^{\mathrm{b}}$ & 0.37 & 0.86 \\
\hline No & Ref & - & - \\
\hline \multicolumn{4}{|l|}{ Evacuation During Hurricane Irene } \\
\hline Evacuated & $3.15^{\mathrm{b}}$ & 2.06 & 4.81 \\
\hline Did not evacuate & Ref & - & - \\
\hline \multicolumn{4}{|l|}{ Zone Awareness } \\
\hline Knew lived in an evacuation zone & $2.17^{\mathrm{b}}$ & 1.13 & 4.17 \\
\hline Knew did not live in an evacuation zone & $0.20^{\mathrm{b}}$ & 0.06 & 0.68 \\
\hline Did not know about zone & Ref & - & - \\
\hline \multicolumn{4}{|l|}{ Poor Physical Health Days } \\
\hline$\geq 14$ days & $0.38^{\mathrm{b}}$ & 0.21 & 0.66 \\
\hline$<14$ days & Ref & - & - \\
\hline
\end{tabular}

${ }^{a}$ Abbreviations: AOR, adjusted odds ratio; $\mathrm{Cl}$, confidence interval; Ref, referent category. Zone A zip codes include 10004, 10005, 10006, 10009, 10038, 10280, 10282, 10303, 10305, 10306, 10307, 10309, 10314, 11096, 11109, 11224, 11231, 11235, 11691, 11692, 11693, 11694, 11695 , and 11697. Covariates include race/ethnicity and education level. bignificant at $P<0.05$.

\section{Limitations}

This study had several limitations. First, this analysis was limited to Registry enrollees who resided in NYC evacuation zone $\mathrm{A}$, and the overall response rate for the Sandy survey was $51 \%$. Many residents were still in the process of recovering from Hurricane Sandy at the time of the survey administration for this study, thus potentially reducing the response rate. Additionally, the NYC evacuation zones are slightly different from the initial study design using FEMA inundation zone, which may have caused a slight reduction in the number of people surveyed. Second, because this study used a sample of individuals who were previously exposed to the 9/11 disaster, our findings may not be generalizable to the general population. Third, data from both the Sandy and Registry wave surveys were self-reported, introducing the possibility of recall bias. Finally, our definition for individuals living in evacuation zone A only included those residing in 
zip codes with $\geq 30 \%$ of the zip code area in zone A, potentially resulting in an underestimate of the population at risk in zone A. Nevertheless, this method of identifying residents in evacuation zone A has been previously used and accepted in other surveys by the NYC Department of Health and Mental Hygiene. Despite these limitations, our study provided a unique examination of evacuation behaviors among a cohort of persons exposed to 9/11. In using Registry data we were able to utilize longitudinal information on demographic characteristics and other factors, including exposures to a prior traumatic event such as $9 / 11$ to assess impact on evacuation behaviors.

\section{CONCLUSION}

Compared to the zone A evacuation rate previously reported $(37 \%),{ }^{5}$ we observed a much higher prevalence of evacuation (57\%) among Registry enrollees who resided in flood-prone areas of NYC during Sandy. Current initiatives put in place after Hurricane Sandy are a great first step to reducing barriers to evacuation. The creation of websites, such as PHEN, that include preparedness and potential risk information, in conjunction with improvements in smartphone technology, could make alerting the public to the dangers of an approaching storm more effective.

Since our findings point to a link between stronger community cohesion and improvements in evacuation compliance, city officials should consider enhancing current disaster messaging to include community-oriented advisories. These messages should encourage individuals to provide assistance to those experiencing barriers to evacuation, such as the elderly or disabled, those with health issues, and families with infants and young children. Moreover, longer-term support for community cohesion could include developing and supporting planning groups in disaster-prone communities. Encouraging and fostering such community participation and engagement among members may result in improved social support and a reduction in barriers to evacuation among those least likely to evacuate.

Being knowledgeable is essential for making informed evacuation decisions. Future disaster communications should also underscore the difference in requirements and logistics for successfully preparing for a disaster. Residents should be aware that the emergency supplies collected for sheltering in place need to be both adequate and sustainable, and those for immediate evacuation should be made mobile and transportable. Additionally, it is imperative that emergency communications clearly and continuously reinforce the importance of timely evacuation once an evacuation warning is issued and inform residents on the risks associated with delayed evacuation. Such campaigns could influence residents' evacuation behaviors during future disasters, improve evacuation success, and consequently reduce disaster-related injuries.

\section{About the Authors}

Bureau of Epidemiology Services (Ms Brown), World Trade Center Health Registry (Dr Gargano, Ms Caramanica, Dr Farfel, Dr Stellman, and Dr Brackbill), and Bureau of Communicable Disease (Ms Parton), New York City Department of Health and Mental Hygiene, Long Island City, New York, and Department of Epidemiology, Mailman School of Public Health, Columbia University, New York, New York (Dr Stellman).

Correspondence and reprint requests to Shakara Brown, MPH, Project Officerl Data Analyst, Bureau of HIV - Field Services Unit, New York City Department of Health and Mental Hygiene, 42-09 28th St, Long Island City, NY, 11101. (e-mail: sbrown25@health.nyc.gov).

\section{Acknowledgments}

We are thankful to Francoise Pickart in the Office of Emergency Preparedness and Response at the New York City Department of Health and Mental Hygiene (NYC DOHMH) for her critical review of this manuscript.

\section{Funding}

This study was supported by Cooperative Agreement Numbers 5U50/ OH009739 and 1E11/OH009630 from the National Institute for Occupational Safety and Health (NIOSH) of the Centers for Disease Control and Prevention (CDC); U50/ATU272750 from the Agency for Toxic Substances and Disease Registry (ATSDR), CDC, which included support from the National Center for Environmental Health, CDC; TP000585-01-Impact of Hurricane Sandy on Morbidity and Mortality in NYC, from the CDC; and by the NYC DOHMH. Its contents are solely the responsibility of the authors and do not necessarily represent the official views of the CDC.

\section{REFERENCES}

1. Hurricane Sandy Rebuilding Strategy: Stronger Communities, a Resilient Region. Hurricane Sandy Rebuilding Task Force. Department of Housing and Urban Development website. http://portal.hud.gov/ hudportal/documents/huddoc?id=hsrebuildingstrategy.pdf. Accessed February, 2015.

2. Gibbs L, Holloway C. Hurricane Sandy after Action Report: Report and Recommendations to Mayor Michael R. Bloomberg. City of New York website. http://www.nyc.gov/html/recovery/downloads/pdf/ sandy_aar_5.2.13.pdf. Accessed Februay, 2014.

3. Subaiya S, Moussavi C, Velasquez A, et al. A rapid needs assessment of the Rockaway Peninsula in New York City after Hurricane Sandy and the relationship of socioeconomic status to recovery. Am J Public Health. 2014;104(4):632-638. http://dx.doi.org/10.2105/AJPH.2013.301668.

4. Know Your Zone. New York City Office of Emergency Management website. http://www.nyc.gov/html/oem/html/get_prepared/know_your_ zone/knowyourzone.html. Accesed February 17, 2015.

5. Brown S, Parton H. Evacuation in New York City during Hurricanes Irene and Sandy. New York City Department of Health and Mental Hygiene: Epi Data Briefs and Data Tables website. http://www.nyc.gov/ $\mathrm{html} / \mathrm{doh} / \mathrm{html} / \mathrm{data} / \mathrm{epidata.shtml}$. Published November 2014. Accessed January 8th, 2015.

6. Brackbill RM, Maliniak M, Stellman SD, et al. Non-fatal injuries 1 week after Hurricane Sandy - New York City Metropolitan Area, October 29, 2012. MMWR Morb Mortal Wkly Rep. 2014;63(42):950-954.

7. Deaths associated with Hurricane Sandy - October - November 2012. MMWR Morb Mortal Wkly Rep. 2013;62(20):393-397.

8. Storm-Related Mortality — Central Texas. October 17-31, 1998. MMWR Morb Mortal Wkly Rep. 2000;49(07):133-135.

9. Faul M, Weller NF, Jones JA. Injuries after Hurricane Katrina among Gulf Coast Evacuees sheltered in Houston, Texas. J Emerg Nurs. 2011; 37(5):460-468. http://dx.doi.org/10.1016/j.jen.2010.12.019.

10. Eisenman DP, Cordasco KM, Asch S, et al. Disaster planning and risk communication with vulnerable communities: lessons from Hurricane 
Katrina. Am J Public Health. 2007;97(suppl 1):S109-S115. http://dx.doi. org/10.2105/AJPH.2005.084335.

11. Brodie M, Weltzien E, Altman D, et al. Experiences of Hurricane Katrina evacuees in Houston shelters: implications for future planning. Am J Public Health. 2006;96(8):1402-1408. http://dx.doi.org/10.2105/ AJPH.2005.084475.

12. Elder K, Xirasagar S, Miller N, et al. African Americans' decisions not to evacuate New Orleans before Hurricane Katrina: a qualitative study [published erratum appears in Am J Public Health. 2007;97(12):2122]. Am J Public Health. 2007;97(suppl 1):S124-S129.

13. Heath SE, Kass PH, Beck AM, et al. Human and pet-related risk factors for household evacuation failure during a natural disaster. Am J Epidemiol. 2001;153(7):659-665. http://dx.doi.org/10.1093/aje/153.7.659.

14. Bateman JM, Edwards B. Gender and evacuation: a closer look at why women are more likely to evacuate for hurricanes. Nat Hazards Rev. 2002;3(3):107-117. http://dx.doi.org/10.1061/(ASCE)1527-6988(2002) 3:3(107)

15. Perry RW. Evacuation Decision-Making in Natural Disasters. Mass Emergencies. 1979;4:25-38.

16. Gershon RRM, Qureshi KA, Rubin MS, et al. Factors associated with high-rise evacuation: qualitative results from the World Trade Center Evacuation Study. Prehosp Disaster Med. 2007;22(3):165-173. http://dx. doi.org/10.1017/S1049023X0000460X.

17. Gershon RRM, Magda LA, Riley HEM, et al. The World Trade Center evacuation study: factors associated with initiation and length of time for evacuation. Fire Mater. 2012;36(5-6):481-500. http://dx.doi.org/10.1002/ fam. 1080.

18. Van Willigen M, Edwards T, Edwards B, et al. Riding out the storm: experiences of the physically disabled during Hurricane Bonnie, Dennis, and Floyd. Nat Hazards Rev. 2002;3(3):98-106. http://dx.doi.org/ 10.1061/(ASCE)1527-6988(2002)3:3(98).

19. Dash N, Gladwin H. Evacuation decision making and behavioral responses: individual and household. Nat Hazards Rev. 2007;8(3):69-77. http://dx.doi.org/10.1061/(ASCE)1527-6988(2007)8:3(69).

20. Stewart AE. Perceptions of Hurricane Destructiveness and Self-Reported Likelihood of Evacuation. Quick Response Research Report 209. University of Colorado Natural Hazards Center website. http://www. colorado.edu/hazards/research/qr/. Published November 2008. Accessed February 17, 2015.

21. Dow K, Cutter SL. Crying wolf: repeat responses to hurricane evacuation orders. Coast Manage. 1998;26(4):237-252. http://dx.doi. org/10.1080/08920759809362356.

22. Farfel M, DiGrande L, Brackbill R, et al. An overview of 9/11 experiences and respiratory and mental health conditions among World Trade Center Health Registry enrollees. J Urban Health. 2008; 85(6):880-909. http://dx.doi.org/10.1007/s11524-008-9317-4.

23. Brackbill RM, Hadler JL, DiGrande L, et al. Asthma and posttraumatic stress symptoms 5 to 6 years following exposure to the World Trade Center terrorist attack. JAMA. 2009;302(5):502-516. http://dx.doi.org/ 10.1001/jama.2009.1121.

24. Ablah E, Konda K, Kelley CL. Factors predicting individual emergency preparedness: a multi-state analysis of 2006 BRFSS data. Biosecur Bioterror. 2009;7(3):317-330. http://dx.doi.org/10.1089/bsp. 2009.0022.
25. Gargano L, Caramanica K, Sisco S, et al. Exposure to the World Trade Center disaster and 9/11-related post-traumatic stress disorder and household disaster preparedness. Disaster Med Public Health Prep. 2015; 9(6):625-633.

26. Strine TW, Neff LJ, Crawford S. Health-related quality of life domains and household preparedness for public health emergencies: Behavioral Risk Factor Surveillance system, 2006-2010. Disaster Med Public Health Prep. 2013;7(2):191-200. http://dx.doi.org/10.1017/dmp.2013.23.

27. Zahran H, Kobau R, Moriarty D, et al. Health-related quality of life surveillance - United States, 1993-2002. MMWR Morb Mortal Wkly Rep. 2005;54(SS-4).

28. Caramanica K, Brackbill R, Stellman S, et al. Posttraumatic stress disorder after Hurricane Sandy among persons exposed to the 9/11 disaster. Int J Emerg Ment Health. 2015;17(1):356-362.

29. Perrin M, DiGrande L, Wheeler K, et al. Differences in PTSD prevalence and associated risk factors among World Trade Center disaster rescue and recovery workers. Am J Psychiatry. 2007;164(9):1385-1394. http://dx.doi. org/10.1176/appi.ajp.2007.06101645.

30. Ghuman SJ, Brackbill RM, Stellman SD, et al. Unmet mental health care need 10-11 years after the 9/11 terrorist attacks: 2011-2012 results from the World Trade Center Health Registry. BMC Public Health. 2014;14(491).

31. Palgi Y, Shrira A, Hamama-Raz Y, et al. Not so close but still extremely loud: recollection of the World Trade Center terror attack and previous hurricanes moderates the association between exposure to Hurricane Sandy and posttraumatic stress symptoms. Compr Psychiatry. 2014; 55(4):807-812. http://dx.doi.org/10.1016/j.comppsych.2014.01.013.

32. Preliminary results from the World Trade Center Evacuation Study New York City. MMWR Morb Mortal Wkly Rep. 2004;53(35):815-817.

33. Heath SE, Champion M. Human health concerns from pet ownership after a tornado. Prehosp Disaster Med. 1996;11(1):67-70.

34. Hunt MG, Bogue K, Rohrbaugh N. Pet ownership and evacuation prior to Hurricane Irene. Animals (Basel). 2012;2(4):529-539. http://dx.doi. org/10.3390/ani2040529.

35. Pets Evacuation and Transportation Standards Act of 2006. Library of Congress website. https://www.congress.gov/bill/109th-congress/housebill/3858?q=\%7B\%22search $\% 22 \% 3 \mathrm{~A} \% 5 \mathrm{~B} \% 22 \mathrm{Pets}+$ evacuation +and+ transportation+standards+act\%22\%5D\%7D. Accessed March 9, 2015.

36. Ready New York: Plan for Hazards. Coastal Storms and Hurricanes Hurricane Evacuation page. New York City Emergency Management website. http://www1.nyc.gov/site/em/ready/hurricane-evacuation.page. Accessed April 12, 2016.

37. Public Health Emergency Network. New York City Department of Health website. http://www.nyc.gov/html/doh/html/em/individuals_ families.shtml. Accessessed August, 18, 2015.

38. Brooklyn Center for Independence of the Disabled (BCID), et al. v. Mayor Bloomberg, et al. Disability Rights Advocates website. http:// dralegal.org/case/brooklyn-center-for-independence-of-the-disabled-bcidet-al-v-mayor-bloomberg-et-al/. Accessed March 31, 2016.

39. Shorris A, Tarlow M. Mayor's Management Report: Preliminary Fiscal 2014, City of New York. New York City Mayor's Office of Operations website. http://www.nyc.gov/html/ops/downloads/pdf/ pmmr2014/2014_pmmr.pdf. Published February 2014. Accessed August 18, 2015. 